\title{
The Dynamics of Learning Engagement in Challenge-based Online Learning
}

\author{
Dirk Ifenthaler \\ Curtin University \\ Bentley, WA, Australia \\ dirk.ifenthaler@curtin.edu.au
}

\author{
David Gibson \\ Curtin University \\ Bentley, WA, Australia \\ david.c.gibson@curtin.edu.au
}

\author{
Longwei Zheng \\ East China Normal University \\ Shanghai, China \\ lwzheng@dec.ecnu.edu.cn
}

\begin{abstract}
Vast amounts of educational data created by learners interacting with digital learning tools open up the opportunity to gain insights for improving education at a new level of evidence-based research into learning and teaching. This study is part of a research programme investigating the dynamics and impacts of learning engagement in a challengebased online learning environment. Learning engagement is a multidimensional concept which includes an individual's ability to behaviourally, cognitively, emotionally, and motivationally engage in an on-going learning process. Challenge-based learning gives significant freedom to the learner to decide what and when to engage and interact with digital learning materials. In light of previous empirical findings, we expect that learning engagement is positively related to learning performance in a challenge-based online learning environment. This study was based on data from the Careers Challenge platform, including transaction data from 8,951 students. Findings indicate that learning engagement in challenge-based online learning environments is, as expected, positively related to learning performance. Implications point toward the need for personalised and adaptive learning environments to be developed in order to cater for the individual needs of learners in challenge-based online learning environments.
\end{abstract}

Keywords- learning engagement; challenge-based online learning; data analytics; time on task; active learning

\section{INTRODUCTION}

In the past few years, research on higher education and especially online learning and teaching has been influenced by several changes. One important driver is the increased availability of vast amounts of educational data with attendant unforeseen possibilities to make use of them [1]. Mining data for insights to improve education enables a new level of evidence-based research into learning and teaching. Hence, the field of learning analytics (LA) is generating growing interest in the integration of data and computer science into the learning sciences including educational research. Much of the current research on LA focusses on technical issues and data processing [2], on data privacy [3], on developing user systems [4], or on specific applications for dashboards [5].

In addition, LA are often discussed and linked with regard to self-regulated learning. One general assumption is that each learning process demands a certain degree of self- regulation [6]. How effective a learner can regulate his or her learning depends on individual characteristics and dispositions [7]. Accordingly, self-regulated learning can be seen as a cyclical process including three major phases: (1) Starting with a forethought phase including task analysis, goal setting, planning, and motivational aspects. (2) The actual learning occurs in the performance phase, i.e., focusing, applying task strategies, self-instruction, and selfmonitoring. (3) The last phase contains self-reflection, as learners evaluate their outcomes versus their prior set goals. To close the loop, results from the third phase will influence future learning activities [6]. Current findings show that facets of self-regulated learning, especially revision, coherence, concentration, and goal setting are related to students' expected support from LA systems [8]. For example, LA can facilitate students through adaptive and personalized recommendations to better plan their learning towards specific goals [9].

A concept closely linked to self-regulated learning is learning engagement [10]. Learning engagement is generally regarded as time and effort an individual invests on a specific learning activity [11]. Several studies focussing on learning engagement support the assumption that a higher engagement of a learner corresponds with higher learning outcomes [12]. However, most of these studies have been conducted in face-to-face learning environments. Accordingly, a confirmation of these findings in online learning environments is still lacking.

This study seeks to close this gap by investigating the dynamics of learning engagement in a challenge-based online learning environment using a data analytics approach.

\section{LEARNING ENGAGEMENT}

A generally accepted assumption is that the more students engage with a subject matter or phenomenon in question, the more they tend to learn [13]. Accordingly, learning engagement is positively linked to desirable learning outcomes or learning performance [14]. Learning engagement is a multidimensional concept and understood as the individual's ability to behaviourally, cognitively, emotionally, and motivationally engage in an on-going learning process [10].

While learning performance is determinant of behaviours [15], several assumptions are linked to the relationship between the performance of an individual and learning 
engagement. For example, Chen [16] investigated the relationship between learning engagement and learning performance of students of ten computer cram schools based in Taiwan. Findings of the multilevel analysis indicate a significant positive relationship between learning engagement and learning performance. Similar findings have been reported in other contexts $[17,18]$.

An impressive number of research studies have been conducted in the field of cognitive load with links to task characteristics and learning engagement [19]. This line of research assumes an active role of the learner in learning processes, i.e., learners select tasks relevant to them [20] and are actively engaged while interacting with the learning environment [21].

In addition, research on reading uses reading time measurements in order to identify learning engagement and linking it to learning performance [22]. The general assumption is that the intensity of mental effort aimed at achieving a greater understanding, i.e., time spent on reading task, is critical during learning. Findings indicate that increased reading times as a sign of greater learning engagement are positively related to learning performance measured as comprehension scores [23,24].

In light of the above empirical findings, we expect that learning engagement is positively related to learning performance in a challenge-based online learning environment. Learning engagement in a challenge-based online learning environment is composed of several actions: (1) launching a specific task, (2) spending active time on the task, (3) entering a written response, and (4) finishing the task. The learning performance measured in this study is computed by the number of correct answers in a subset of tasks designed with embedded feedback to the student. The specific hypotheses of this study are as follows:

H1: Launching tasks is related to the learning performance.

$\mathrm{H} 2$ : Spending active time on tasks is related to the learning performance.

H3: The length of written responses is related to the learning performance.

H4: Finishing tasks is related to the learning performance.

\section{Curtin Challenge Digital Learning PlatForm}

The Curtin Challenge digital learning platform (http://challenge.curtin.edu.au) supports individual and teambased learning via gamified, challenge-based, open-ended, inquiry-based learning experiences that integrate automated feedback and rubric-driven assessment capabilities. Currently, there are three Challenges offered by Curtin University: Careers, Leadership, and English Language Proficiency. Each Challenge comprises more than ten modules that each take about an hour to complete and can be stopped and started at any time. Each module includes about five interactive and engaging activities.

This paper includes analysis from the Careers Challenge, which has 14 modules that can each normally be completed in one hour or less (see Figure 1). The design features of each module contain approximately five activities that might include one to three different learner interactions or tasks.

For example, the module Who am $I$ in the Careers Challenge is a collection of five activities containing learning interactions, such as choosing from among options, writing a short response to a prompt, spinning a wheel to create random prompts, creating, organising, and listing ideas, or matching items. Each page can contain one or several such interactions, and the learner does not have to submit the page in order for the data to be captured. Data is constantly being captured, which creates information about the timing, sequence, and completeness as well as the content of the interactions (i.e., navigation event). The data record is thus highly granular, providing an opportunity to examine the dynamics of the activity as well as the contents of the artefacts created by the learner for every click on every page for every user.

\section{METHOD}

\section{A. Data Source}

The data set consists of $1,577,487$ rows and contains information of $N=8,951$ students (3,402 male; 5,036 female; 513 unspecified) with an average age of $M=25.20$ years $(S D=6.59)$, enrolled in the Careers Challenge. They spent a total of 9,415 hours interacting with the Careers Challenge in a period of 24 months (January 2016 - January 2018). Figures 2 and 3 provide an overview of modules completed for the Careers Challenge as well as the interaction (launched, completed, being active, dropped) in specific activities.

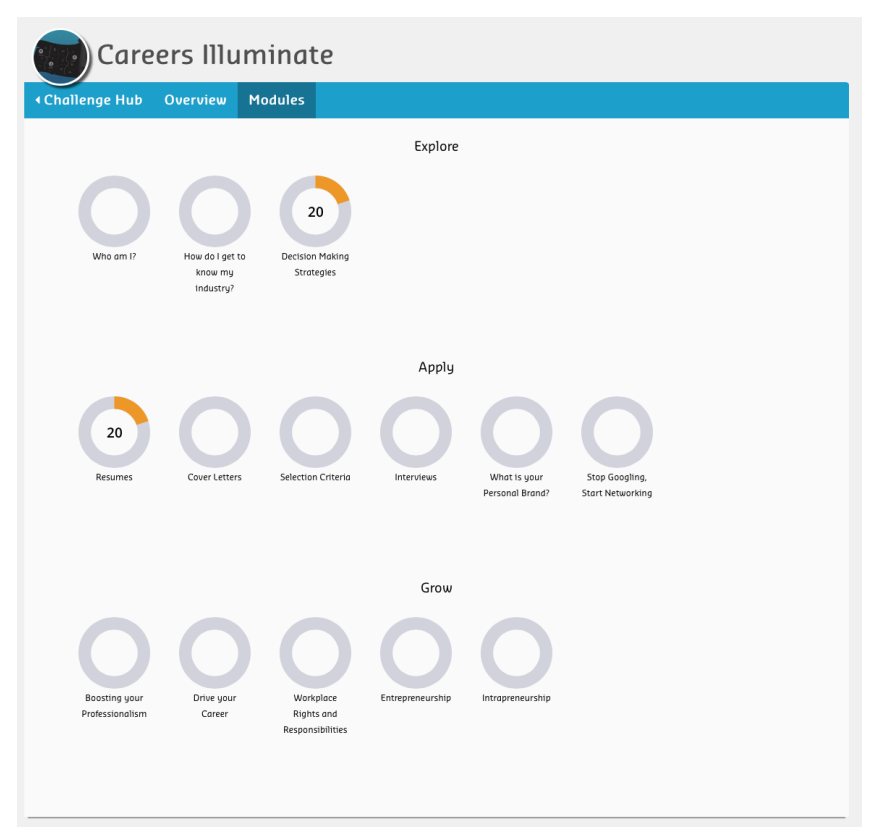

Figure 1. Module selection in the Careers Challenge. 


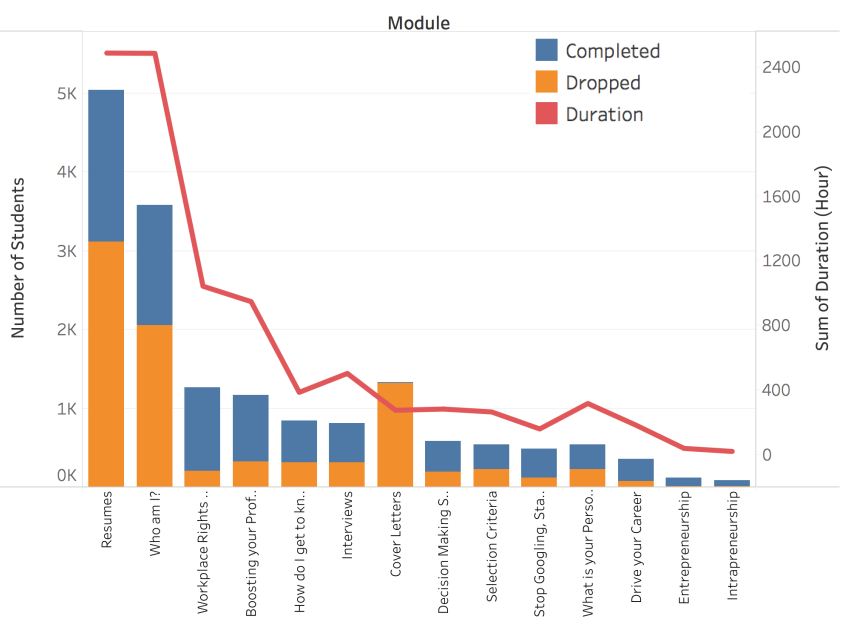

Figure 2. Modules completed and dropped in the Careers Challenge.

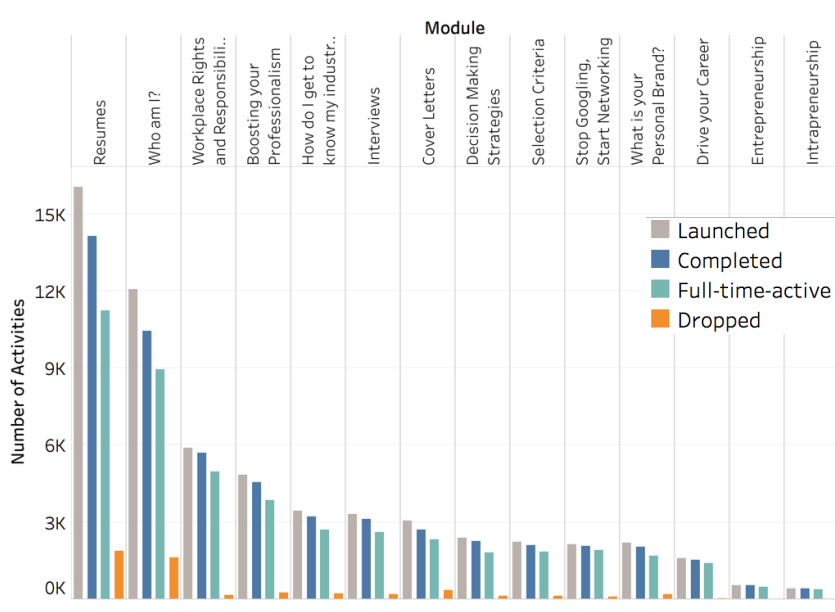

Figure 3. Activities interaction in the Careers Challenge.

\section{B. Data Analytics Strategy}

The raw data from the Careers Challenge platform were cleaned and transformed into a transaction data set in which each row represents an event of one user. The dependent variable learning performance (LP) was computed as the number of correct answers in an activity. The predictor variables were computed as follows: launching_task (LT) as the number of activities started by a student; time on task (TT) as the duration in seconds spent in an activity; written_response (WR) as the number of words submitted by a student; finishing task (FT) as the number of activities finished by a student.

\section{RESULTS}

We used a regression analyses to determine whether launching tasks, time on task, finishing tasks, and written responses were significant predictors of students' learning performance in the Careers Challenge. Descriptive statistics are shown in Table 1.
TABLE I. ZERO-ORDER CORRELATIONS OF STUDENTS' LEARNING ENGAGEMENT AND LEARNING PERFORMANCE IN THE CAREERS CHALLENGE

\begin{tabular}{|c|c|c|c|c|c|}
\hline & \multicolumn{5}{|c|}{ Zero-Order $r$} \\
\hline & LT & $\mathrm{TT}$ & WR & FT & $\mathrm{LO}$ \\
\hline LT & - & & & & \\
\hline TT & $.771 * * *$ & - & & & \\
\hline WR & $.724 * * *$ & $.685 * * *$ & - & & \\
\hline FT & $.355 * * *$ & $.290 * * *$ & $.331 * * *$ & - & \\
\hline LP & $.817 * * *$ & $.610 * * *$ & $.660 * * *$ & $.332 * * *$ & - \\
\hline $\begin{array}{l}\text { Note. } \\
\text { TT }= \\
N=8\end{array}$ & $\begin{array}{l}k^{*} p<.00 \\
\text { ne on tas } \\
51\end{array}$ & $\begin{array}{l}\mathrm{LP}=\text { lear } \\
\mathrm{NR}=\text { wri }\end{array}$ & $\begin{array}{l}\text { ng outcon } \\
\text { n respons }\end{array}$ & $\begin{array}{l}\mathrm{LT}=\text { lau } \\
\mathrm{FT}=\text { finis }\end{array}$ & $\begin{array}{l}\text { ig tasl } \\
\text { task; }\end{array}$ \\
\hline
\end{tabular}

TABLE II. REGRESSION ANALYSIS PREDICTING LEARNING PERFORMANCE IN THE CAREERS CHALLENGE RELATED TO DYNAMICS OF LEARNING ENGAGEMENT

\begin{tabular}{lccccc}
\hline & $R^{2}$ & $\Delta R^{2}$ & $B$ & $S E B$ & $\beta$ \\
\hline LP & .682 & .682 & & & \\
LT & & & .842 & .012 & $.76^{* * *}$ \\
TT & & & .000 & .000 & $-.10^{* * *}$ \\
FT & & & .080 & .014 & $.04 * * *$ \\
WR & & .006 & .000 & $.17^{* * *}$ \\
\hline Note *** $p<.001 ;$ LP $=$ learning performance; LT $=$ launching
\end{tabular}

Note. ${ }^{* * *} p<.001 ; \mathrm{LP}=$ learning performance; $\mathrm{LT}=$ launching task; TT $=$ time on task; FT $=$ finishing task; $\mathrm{WR}=$ written response; $N=8,951$

The linear regression analyses are presented in Table 2, yielding a $\Delta R^{2}$ of $.682(F(4,8950)=4805.17, p<.001)$. Clearly, the number of activities started by a student (LT; $\beta=$ $.76, p<.001)$ positively predicted the learning performance. In addition, the number of activities finished by a student (FT; $\beta=.04, p<.001$ ) and the number of words submitted by a student (WR; $\beta=.17, p<.001$ ) positively predicted the learning performance. In contrast, the duration students spent on a task (TT; $\beta=-.10, p<.001)$ was negatively correlated to the learning performance.

In sum, all four hypotheses are accepted, confirming a relationship between learning engagement and learning performance in challenge-based online learning environments.

\section{DISCUSSION}

\section{A. Significance of Findings}

Learners differ in their reasons for engaging in learning tasks [25]. These interindividual differences require personalised support while learning [25]. In addition, research also reports intraindividual differences in engagement, i.e., during the learning dependent-progression the engagement changes over time and requires adaptive support to cater for the learners' needs [26].

This study aimed to investigate the dynamics of engagement in challenge-based online learning environments and its relationship to learning performance. Hypotheses were developed based on previous research from face-to-face learning environments. Our analysis was based on data from the Careers Challenge platform, including transaction data from 8,951 students. The current study provides 
contributions to the literature and implications for researchers in the field of learning analytics as well as practitioners in online learning.

The analytic results showed that learning engagement in challenge-based online learning environments is significantly related to learning performance. These findings support previous studies conducted in face-to-face situations $[16,17,18]$. Significant indicators predicting the learning performance of the student appeared to be the number of activities started and the number of activities finished by a student. This is a reflection of active engagement with the learning environment [19]. At the same time, better learners seem to spend less time on a specific task. This may be interpreted as a reflection of existing prior knowledge or a progression towards an advanced learner [26]. Another significant indicator predicting learning performance was the number of words submitted in open text activities. On a surface level, these findings are also related to studies conducted in writing research and clearly reflect the impact of the variation in learning engagement [22,23].

\section{B. Limitations}

This study and its findings are limited in several aspects that must be addressed. First, due to limited access of student data, for example, course load, past academic performance, or personal characteristics, linking additional data to the reported engagement and performance measures has not yet occurred. Combining such additional data, we expect will provide a more detailed insight into the multidimensional concepts to be investigated in a future study. Second, the Careers Challenge did not include an overall performance measure which has been validated against an outside criterion. Accordingly, a revision of the learning and assessment design should include additional or revised measures which follow accepted criteria or competence indicators. However, without the externally validated benchmarks, there is sufficient available data from the Careers Challenge which can be used to improve the existing learning design through algorithms focussing on design features and navigation sequences of learners [27,28]. Third, as we included the analysis of open text answers in our analysis model, this approach is limited by the overall potential of the simple approach natural language processing (NLP). Further development of our analysis in future studies will include a focus on deeper levels of syntactic complexity, lexical sophistication, and quality of writing as well as a deep semantic analysis compared to expert solutions [29,30].

\section{Implications and Future Research}

Analyses of the learning performance transcript, even when automated and multileveled, is a mixture of conditional and inferential interpretation that can utilize several frames of reference while adding layers of interpreted evidence, insights concerning the complexity and additional dimensionality to our understanding of the performance and our ability to re-present the performance in the light of our understandings [31].

The Curtin Challenge is a mobile ready interactive learning delivery platform that illustrates several features of game-inspired challenge-based learning while adding a layer of big data collection to enable research into teaching and learning [31]. A learner interacts with Curtin Challenge content by pointing, clicking, sliding items, vocalizing, taking pictures and drawing as well as watching, listening, reading, and writing as in traditional e-learning. The more highly engaging interactions occur more often (i.e., every few seconds) than in passive traditional e-learning. Key to learning engagement is having a compelling storyline, situating the learner as a prime actor in the story, and creating urgency of action through curiosity, humor, relevance, and individual or collaborative team pressures to produce and succeed.

The Curtin Challenge platform is being developed to support both individual and team-based learning in primarily open-ended ill-structured problem solving and project-based learning contexts [32]. The platform can also support selfguided learning, automated feedback, branching story lines, self-organizing teams, and distributed processes of mentoring, learning support and assessment [31].

The data traces captured by the platform are highly detailed, with many events per learning activity, which brings the potential for measuring indicators of physical, emotional and cognitive states of the learner. The data innovation of the Curtin Challenge platform is the ability to capture event-based records of higher frequency with the potential to analyze higher dimensional aspects of learning engagement, which we believe may be in turn useful for analysis of the embedded teaching design's effectiveness and impact on the physical, emotional and cognitive layers of learning caused or influenced by digital engagements. The data from the challenge-based learning platform forms a high-resolution analytics base on which researchers can conduct studies into teaching and learning and into how to achieve better outcomes in scalable digital learning experiences [33].

Future research will focus on the analysis of several large extant data sets from the Curtin Challenge platform. Currently, the possibility of adaptive algorithms based on learning engagement and learning performance are being investigated. Such algorithms will enable meaningful micro analysis of individual performance as well as personalised and adaptive feedback to the learner whenever it is needed.

\section{ACKNOWLEDGMENT}

This work is part of the UNESCO Chair of Data Science in Higher Education Learning and Teaching (http://www.curtin.edu.au/UNESCO) which focusses on advancing global knowledge, practice and policy in applying data science to transform higher education learning and teaching that improves personalization, access and effectiveness of education for all.

\section{REFERENCES}

[1] P. D. Long, and G. Siemens, "Penetrating the fog: Analytics in learning and education," EDUCAUSE Review, vol. 46, no. 5, pp. 3140, 2011 .

[2] M. Berland, R. S. J. d. Baker, and P. Bilkstein, "Educational data mining and learning analytics: Applications to constructionist 
research," Technology, Knowledge and Learning, vol. 19, no. 1-2, pp. 205-220, 2014.

[3] D. West, H. Huijser, and D. Heath, "Putting an ethical lens on learning analytics," Educational Technology Research and Development, vol. 64, no. 5, pp. 903-922, 2016.

[4] M. d'Aquin, S. Dietze, E. Herder, H. Drachsler, and D. Taibi, "Using linked data in learning analytics," eLearning Papers, vol. 36, pp. 1-9, 2014.

[5] L. D. Roberts, J. A. Howell, and K. Seaman, "Give me a customizable dashboard: personalized learning analytics dashboards in higher education," Technology, Knowledge and Learning, vol. 22, no. 3, pp. 317-333, 2017.

[6] B. J. Zimmerman, "Becoming a self-regulated learner: An overview," Theory into Practice, vol. 41, no. 2, pp. 64-70, 2002.

[7] M. Bannert, "Promoting self-regulated learning through prompts," Zeitschrift für Pädagogische Psychologie, vol. 23, no. 2, pp. 139-145, 2009.

[8] D. Gašević, S. Dawson, and G. Siemens, "Let's not forget: Learning analytics are about learning," TechTrends, vol. 59, no. 1, pp. 64-71, 2015.

[9] C. McLoughlin, and M. J. W. Lee, "Personalized and self regulated learning in the Web 2.0 era: International exemplars of innovative pedagogy using social software," Australasian Journal of Educational Technology, vol. 26, no. 1, pp. 28-43, 2010.

[10] C. A. Wolters, and D. J. Taylor, "A self-regulated learning perspective on student engagement," Handbook of research on student engagement, S. Christenson, A. Reschly and C. Wylie, eds., pp. 635-651, Boston, MA: Springer, 2012.

[11] G. D. Kuh, "What student affairs professionals need to know about student engagement," Journal of College Student Development, vol. 50, no. 6, pp. 683-706, 2009.

[12] R. M. Carini, "Engagement in learning," Encyclopedia of the sciences of learning, N. M. Seel, ed., pp. 1153-1156, Boston, MA: Springer, 2012.

[13] R. M. Carini, G. D. Kuh, and S. P. Klein, "Student engagement and student learning: testing the linkages," Research in Higher Education, vol. 47, no. 1, pp. 1-32, 2006.

[14] S. P. Klein, G. D. Kuh, M. Chun, L. Hamilton, and R. Shavelson, "An approach to measuring cognitive outcomes across higher education institutions," Research in Higher Education, vol. 46, no. 3, pp. 251$276,2005$.

[15] A. Bandura, "Perceived self-efficacy in cognitive development and functioning," Educational Psychologist, vol. 28, no. 2, pp. 117-148, 1993.

[16] I.-S. Chen, "Computer self-efficacy, learning performance, and the mediating role of learning engagement," Computers in Human Behavior, vol. 72, pp. 362-370, 2017.

[17] W. Lin, L. Wang, P. A. Bamberger, Q. Zhang, H. Wang, W. Guo, J. Shi, and T. Zhang, "Leading future orientations for current effectiveness: The role of engagement and supervisor coaching in linking future work self salience to job performance," Journal of Vocational Behavior, vol. 92, pp. 145-156, 2016.

[18] A. Pourbarkhordari, E. H. I. Zhou, and J. Pourkarimi, "How individual-focused transformational leadership enhances its influence on job performance through employee work engagement," International Journal of Business and Management, vol. 11, no. 2, pp. 249-261, 2016.

[19] F. Kirschner, L. Kester, and G. Corbalan, "Cognitive load theory and multimedia learning, task characteristics and learning engagement: The Current State of the Art," Computers in Human Behavior, vol. 27, no. 1, pp. 1-4, 2011.

[20] G. Corbalan, L. Kester, and J. J. G. van Merriënboer, "Learnercontrolled selection of tasks with different surface and structural features: Effects on transfer and efficiency," Computers in Human Behavior, vol. 27, pp. 76-81, 2011.
[21] A. Schwamborn, H. Thillmann, M. Opfermann, and D. Leutner, "Cognitive load and instructionally supported learning with provided and learner-generated visualizations," Computers in Human Behavior, vol. 27, pp. 89-93, 2011.

[22] A. C. Graesser, K. K. Millis, and R. A. Zwaan, "Discourse comprehension," Annual Review of Psychology, vol. 48, pp. 163-189, 1997.

[23] B. W. Miller, R. C. Anderson, J. Morris, T. J. Lin, M. Jadallah, J. Sun, and T. D., "The effects of reading to prepare for argumentative discussion on cognitive engagement and conceptual growth," Learning and Instruction, vol. 33, pp. 67-80, 2014.

[24] B. W. Miller, "Using reading times and eye-movements to measure cognitive engagement," Educational Psychologist, vol. 50, no. 1, pp. $31-42,2015$.

[25] D. H. Schunk, and B. J. Zimmerman, Self-regulation of learning and performance: Issues and educational applications, Hillsdale, NJ: Erlbaum, 1994.

[26] D. Ifenthaler, and N. M. Seel, "The measurement of change: Learning-dependent progression of mental models," Technology, Instruction, Cognition and Learning, vol. 2, no. 4, pp. 317-336, 2005.

[27] R. Agrawal, B. Golshan, and E. Papalexakis, "Toward data-driven design of educational courses: A feasibility study," Journal of Educational Data Mining, vol. 8, no. 1, pp. 1-21, 2016.

[28] L. Lockyer, E. Heathcote, and S. Dawson, "Informing pedagogical action: Aligning learning analytics with learning design," American Behavioral Scientist, vol. 57, no. 10, pp. 1439-1459, 2013.

[29] S. A. Crossley, "Advancing research in second language writing through computational tools and machine learning techniques," Language Teaching, vol. 46, no. 2, pp. 256-271, 2013.

[30] D. Ifenthaler, "AKOVIA: Automated Knowledge Visualization and Assessment," Technology, Knowledge and Learning, vol. 19, no. 1-2, pp. 241-248, 2014.

[31] D. C. Gibson, and D. Ifenthaler, "Analysing performance in authentic digital scenarios," Authentic learning through advances in technologies, T.-W. Chang, R. Huang and Kinshuk, eds., pp. 17-27, New York, NY: Springer, 2018.

[32] D. Eseryel, V. Law, D. Ifenthaler, X. Ge, and R. B. Miller, "An investigation of the interrelationships between motivation, engagement, and complex problem solving in game-based learning," Journal of Educational Technology \& Society, vol. 17, no. 1, pp. 4253, 2014.

[33] D. C. Gibson, and P. Jackl, "Theoretical considerations for gamebased e-learning analytics," Gamification in education and business, T. Reiners and L. Wood, eds., pp. 403-416, New York, NY: Springer, 2015 . 
